\title{
Innovative Staff Training Strategies for the Tourism and Hospitality Industry
}

\author{
Mikhail Morozov \\ Plekhanov Russian University of Economics \\ Russian New University \\ Moscow, Russia \\ E-mail:mmorozov@bk.ru
}

\author{
Natalia Morozova \\ Russian New University \\ Moscow, Russia \\ E-mail: sks@rosnou.ru
}

\begin{abstract}
The article discusses innovative approaches to staff training for the tourism and hospitality industry. The main changes in the system of personnel training are related to digitalization, which radically changes business processes in all spheres of the economy, including the tourism and hospitality industry. The influence of digital technologies on changes in the composition of the competencies of tourism and hotel business has been studied. It is shown that when forming the strategy of personnel training for the tourist industry, the formation of digital competences acquires special significance.
\end{abstract}

Keywords-tourism; hospitality; digital technologies; digital competencies

\section{INTRODUCTION}

The modern development of tourism and hotel business is directly related to the emergence of information and communication technologies, which have a huge impact on the tourism industry as a whole, and on the tourists themselves. Digital technologies are based on fundamentally new approaches to information processing, including artificial intelligence, big data technologies, Internet of Things, mobile technologies, blockchain, etc.

Digitalization affects all spheres of human life, forms new channels of communication, such as social networks and various instant messengers, which have already become an integral attribute of interpersonal communication. Digital technologies lead to the transformation of human behavior, quickly alter the needs of tourists, for whom permanent access to the Internet becomes commonplace. In tourism, they even began to use the new term electronic nomad, whose characteristic attributes of life were gadgets and constant access to the Internet. The key condition for a comfortable journey was the constant availability of the Internet and the availability of various mobile applications for tourists.

An important competitive advantage of a tourist product is its information support, which contains the maximum amount of information necessary for a traveler. According to Travelport, when planning a trip, $80 \%$ of Russian tourists use video and photos of the chosen tourist destination and its attractions, $75 \%$ of tourists leave their reviews, $69 \%$ want to get the maximum possible amount of information about the destination.

Tourists are actively using mobile services that provide convenient and comfortable digital communication. There are several groups of mobile services for travelers [1]:

- cartographic services

- geographic information systems

- audio guides

- reference catalogs with reviews and tips

- booking air tickets

- hotel booking

- booking of train tickets

- car rental and taxi

- reference information on catering enterprises

- weather background information

- accounting of finance

- translators

- messengers

- travel organizers

- additional services

Currently, there is a digitalization of business processes in the field of tourism and hospitality, therefore, changing requirements for the level of competence of personnel of enterprises of the tourist and hotel industry. In this regard, the modernization of the training system that meets the future needs of the digital tourism industry is of particular importance.

\section{METHODS AND MATERIALS}

During the study, monographic, statistical, economicanalytical, comparative methods were used. On their basis, statistical data on the level of development of information and communication technologies were analyzed, the degree 
In this regard, the level of requirements for employees of the tourist and hotel industry in terms of possession of modern information and communication technologies is increasing.

The development of digital technologies involves the continuous improvement of staff in the tourism and hospitality industry. Obsolescence of knowledge will occur at a faster pace than today. In this regard, continuous lifelong learning will be demanded, the paradigm of education will drastically change, the level of staff mobility will increase, and the technology of working out of the office will expand [9]. The development of information and communication technologies will contribute to the spread of cross-border remote employment.

The data on the number of specialists of the highest and medium qualifications in the field of information and communication technologies (ICT) were analyzed. "Fig. 1" shows the share of ICT specialists in the total number of people employed by individual countries [10].

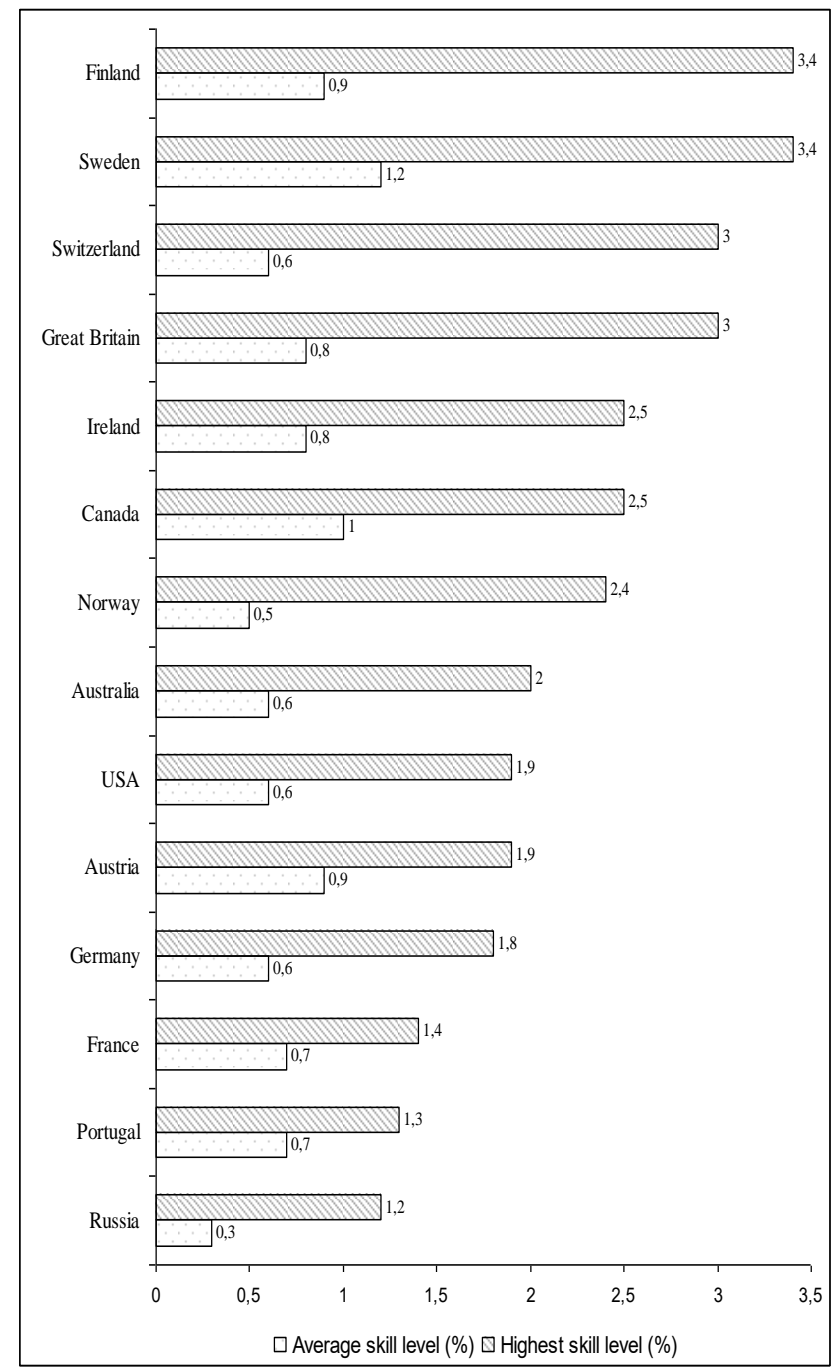

Fig. 1. Share of specialists in the field of information and communication technologies in\% of the total number of employees in 2017.

It was found that in terms of the development of the digital economy, the share of information and 
example, Unilever, are already developing and implementing internal training programs for personnel using social networks and cognitive technologies. In order to maintain their competitiveness, it is advisable for companies to maintain and promote the ideology of continuous staff training.

\section{RESULTS AND DISCUSSION}

A characteristic feature of tourist activity is a high informative capacity, the presence of large information flows, their constant updating and high speed of exchange operations. Informational interrelations exist between all participants of the tourist market, however, special attention is paid to information intended for end users (tourists). This is due to the need to provide the most comprehensive information necessary to make a decision about the trip and used during the trip. The quality of information and communication support of tourism activities is a major factor in competitiveness in tourism. Based on this, when training for the tourism and hospitality industry, special importance is given to the formation of the information and communication competence of a specialist.

In the context of the transition to a digital economy, it is necessary to strengthen the formation of digital competencies in the training of personnel for the tourism industry and hotel business. Training programs will need to provide for the formation of specialized digital skills related to solving complex professional problems in the digital environment, the skills of high-tech professions (programmers, webdesigners, big data analysts, etc.).

The key competencies of the tourism and hospitality industry in the digital economy include:

- concentration and attention management

- digital competence

- creativity

- ability to self-study

- environmental thinking

- cross-cultural skills

In the Russian federal state educational standards in the areas of training "Tourism" and "Hospitality" the formation of digital competencies is assumed within the framework of the general professional competence. This competence implies the ability to apply technological innovations and modern software in the tourism sector. For the formation of this competence introduced the discipline "Information and communication technologies in tourism activities." It consists of two parts: "Information and communication and GIS technologies in tourism" and "Software and automation of tourism enterprises".

In the "Tourism" direction of training it is recommended to use the following automated systems (one or more of the educational organization's choice): SAMO-Tour, LeaderTour, TourManager, Master-Tour, Tourist Office, IntourSoft, ANTGroup, Edelweiss, Barsum, Rekonline, 
competencies. When developing educational programs, it is proposed to take into account the innovative prospects for the development and digitalization of the tourism and hospitality sphere. In our opinion, it is advisable to conduct a study "Foresight competence in the tourism industry 2030", which will allow to identify the necessary digital competencies for workers in the tourism industry.

In educational programs it is necessary to provide an increased level of digital competencies. This means that training requires not only the development of skills in the field of information and communication technologies and specialized software, but also deeper digital competencies. These include skills in working with IoT technologies, information security and confidentiality (cybersecurity), programming skills, etc.

\section{REFERENCES}

[1] M. A. Morozov and N. S. Morozova, "The impact of mobile applications on the development of the tourism industry," Bulletin of the National Academy of Tourism, 2015, №4 (36), pp. 17-19.

[2] D. Radovanović, B. Hogan, and D. Lalić, "Overcoming digital divides in higher education: Digital literacy beyond Facebook," New Media and Society, 2015, 17(10), pp. 1733-1749.

[3] M. Spante1, S. Sofkova, M. Lundin, and A. Algers. Digital competence and digital literacy in higher education research: Systematic review of concept use, Cogent Education, 2018.

[4] M. Linares, D. Romero, "Developing a Multidimensional Checklist for Evaluating Language-Learning Websites Coherent with the Communicative Approach: A Path for the Knowing-How-To-Do," Enhancement Interdisciplinary Journal of e-skills and Life Long Learning, 2016, 12, pp. 57-93.

[5] M. A. Morozov and N. S. Morozova, "The development of a digita service economy and its impact on the labor market,"Service Plus, 2018, V.12, №1, pp. 94-101.

[6] M. Morellato, "Digital competence in tourism education: cooperativeexperiential learning," Journal of Teaching in Travel \& Tourism, 2014, 14(2), pp. 184-209.

[7] M. A. Morozov and N. S. Morozova, Information technology in the tourism industry. Moscow, KNORUS, 2017.

[8] The concept of effective business in the field of new solutions, projects and hypotheses, Moscow, Dashkov and K, 2018.

[9] N. S. Morozova, "Features of personnel management in a digital economy," Moscow, Editorial and Publishing House of RosNOU, 2018.

[10] Enterprise Development: Concepts, Digital Technologies, Efficient System, Moscow, Dashkov and K, 2019.
- artificial intelligence

- mobile technologies that are already actively used in the tourism and hospitality industry

Obviously, competition will intensify as the digital economy develops. Competitive advantages will be acquired by those companies that will be able to quickly introduce new technological and managerial changes related to the digitalization of the economy, adapt and accept new requirements for running a digital business.

\section{CONCLUSION}

The introduction of digital technologies in the tourism and hospitality industry creates new staffing requirements that are associated with the development of digital skills and 